\title{
Unrelated cord blood transplantation for childhood acute myeloid leukemia: a Eurocord Group analysis
}

Gerard Michel, Vanderson Rocha, Sylvie Chevret, William Arcese, Kah-Wah Chan, Alexandra Filipovich, Tsuneo A. Takahashi, Marcus Vowels, Juan Ortega, Pierre Bordigoni, Peter J. Shaw, Isaac Yaniv, Alexandra Machado, Pedro Pimentel, Franca Fagioli, Amparo Verdeguer, Jean Pierre Jouet, Blanca Diez, Euripedes Ferreira, Ricardo Pasquini, Joseph Rosenthal, Eric Sievers, Chiara Messina, Anna Paola lori, Federico Garnier, Irina Ionescu, Franco Locatelli, and Eliane Gluckman, for the Eurocord Group

\begin{abstract}
Results of unrelated cord blood transplantation (UCBT) in childhood acute myeloid leukemia (AML) have not been previously reported. We analyzed 95 children receiving UCB transplants for AML (20 in first complete remission [CR1], 47 in CR2, and 28 in more advanced stage). Poor prognosis cytogenetic abnormalities were identified in 29 cases. Most patients received a 1 or 2 HLA antigens-mismatched UCB transplants. The median number of collected nucleated cells (NCs) was $5.2 \times 10^{7} /$ kg. Cumulative incidence $(\mathrm{Cl})$ of neutro-
\end{abstract}

phil recovery was $78 \% \pm 4 \%$, acute graftversus-host disease (GVHD) was $35 \% \pm 5 \%$, and 100-day transplantation-related mortality (TRM) was $20 \% \pm 4 \%$. In multivariable analysis, a collected NC dose higher than $5.2 \times 10^{7} / \mathrm{kg}$ was associated with a lower 100-day TRM. The 2-year $\mathrm{Cl}$ of relapse was $29 \% \pm 5 \%$ and was associated with disease status. The 2-year leukemia-free survival (LFS) was $42 \% \pm 5 \%(59 \% \pm 11 \%$ in CR1, $50 \% \pm 8 \%$ in CR2, and $21 \% \pm 9 \%$ for children not in CR). Children with poor prognosis cytogenetic features had simi- lar LFS compared with other patients ( $44 \% \pm 11 \%$ vs $40 \% \pm 8 \%$ ). In CR2, LFS was not influenced by the length of CR1 (53\% $\pm 11 \%$ in CR1 $<9.5$ months compared with $50 \% \pm 12 \%$ in later relapses). We conclude that UCBT is a therapeutic option for children with very poorprognosis AML and who lack an HLAidentical sibling. (Blood. 2003;102: 4290-4297)

๑ 2003 by The American Society of Hematology

\section{Introduction}

Bone marrow transplantation (BMT) from an HLA-matched sibling or unrelated donor plays a major role in the treatment of children with relapsed acute myeloid leukemia (AML). ${ }^{1-6}$ However, although there are currently more than 8 million donors registered in marrow donor registries around the world, a substantial proportion of children who lack a sibling donor will never undergo BMT from an HLA-matched unrelated donor either because such a donor cannot be found or because the time to identify a donor is too long. Moreover, for those children who received unrelated bone marrow transplants, increased HLA disparity adversely affects survival because of high risk of graft-versus-host disease (GVHD) and opportunistic infections. ${ }^{7-9}$ The use of haploidentical family donors provides a potential source of hematopoietic stem cells for children who lack both a sibling and an unrelated donor. ${ }^{10-11}$ T-cell depletion of the graft can in part overcome the risk of severe GVHD, but it substantially increases the risk of severe and prolonged posttransplantation immunodeficiency.

Hematopoietic stem cells from an unrelated cord blood (UCB) transplant can restore hematopoiesis and immune function after a myeloablative conditioning regimen, even if the graft is not perfectly HLA identical to the recipient. ${ }^{12-15}$ This important medical advance led to the establishment of large cord blood banks that made possible the use of UCB to provide transplants for patients who lack a conventional related or unrelated donor. In addition, UCB offers the advantage of significantly faster availability of banked cryopreserved UCB units compared with the availability of unrelated bone marrow grafts. ${ }^{16}$

The efficacy of BMT in AML is at least partially linked to a graft-versus-leukemia effect (GVL), which is mediated by the engrafted $\mathrm{T}$ lymphocytes and is statistically associated with the clinical manifestations of graft-versus-host disease (GVHD). GVHD
From the Department of Medicine, University of Marseille, Marseille, France Eurocord office, Paris, France; Biostatistics Department, St Louis Hospital, University of Paris 7, France; Department of Hematology, University La Sapienza Rome, Italy; MD Anderson Cancer Center, Houston, TX; Children's Hospital Medical Center, Cincinnati, OH; Tokyo Cord Blood Bank, Tokyo, Japan; Sydney Children's Hospital, Sydney, Australia; Hospital Infantil Vall d'Hebron, Barcelona, Spain; Hôpital d'Enfants, Nancy, France; The New Children's Hospital, Sydney, Australia; Schneider Children's Hospital, Petach-Tikva, Israel; Inst Portugues de Oncologia Lisboa, Portugal; Inst Portugues de Oncologia, Porto, Portugal; Ospedale Regine Margherita, Torino, Italy; Hospital Infantil La Fe, Valencia, Spain; Claude Huriez Hospital, Lille, France; Fleni, Buenos Aires, Argentina; Hospital Israelita Albert Einstein, Sao Paulo, Brazil; Hospital de Clinicas, Curitiba, Brazil; City of Hope Medical School, Duarte, CA; Fred Hutchinson Cancer Research Center (FHCRC), Seattle, WA; Clinica Oncoematologica Pediatrica, Padova, Italy; Oncoematologia Pediatrica, Istituto di Ricovero e Cura a Carattere Scientifico Policlinico San Matteo, Pavia, Italy.

Submitted April 24, 2003; accepted August 4, 2003. Prepublished online as Blood First Edition Paper, August 14, 2003; DOI 10.1182/blood-2003-04-1288.
A complete list of the members of the Eurocord Group appears in the "Appendix."

Presented in abstract form at the 44th annual meeting of the American Society of Hematology, Philadelphia, PA, December 6-10, 2002.

Supported by an European Union grant for Eurocord BIOMED II QLRT-199900380 and QLK3-CT-2002-01918.

Reprints: Eliane Gluckman, Eurocord Registry-Hospital Saint Louis AP/HP, Department of Hematology and Bone Marrow Transplantation and Clinical Research Laboratory on Cell Therapy, Paris University 7, 1 Ave Claude Vellefaux, 75010 Paris, France; e-mail: eliane.gluckman@sls.ap-hop-paris.fr.

The publication costs of this article were defrayed in part by page charge payment. Therefore, and solely to indicate this fact, this article is hereby marked "advertisement" in accordance with 18 U.S.C. section 1734.

(C) 2003 by The American Society of Hematology 
is less frequent after UCB transplantation (UCBT) than after unrelated bone marrow transplantation (UBMT). ${ }^{17}$ This particular characteristic of UCBT could raise theoretical concerns about the efficacy of this kind of transplantation in childhood AML that cannot currently be clinically clarified because there are very few data in the literature reporting specific results and prognostic factors of UCBT in childhood AML. In a previous Eurocord comparative study of children receiving UCB transplants or UBM transplants for acute leukemia, relapse rate was not increased after UCBT. ${ }^{17}$ However, it was not possible to report specific data for children with AML at different stages of their disease because of the relatively small number of patients in each subgroup. Using data from the Eurocord registry, we are now able to report outcomes and their association with patient-, disease-, and transplant-related factors in 95 children who underwent UCBT for AML.

\section{Patients, materials, and methods}

\section{Patients' selection criteria}

All children reported to the Eurocord registry as having undergone UCBT for AML were included in this study, with the exception of those with either Down syndrome $(n=2)$ or Fanconi anemia $(n=2)$. Ninety-five children aged 16 years or younger were analyzed. They received transplants from 1994 through March 2002 in 49 centers from 17 countries. Approval for this study was obtained from the Eurocord institutional review board. Informed consent was provided according to the Declaration of Helsinki.

\section{Patient characteristics}

The characteristics of the 95 children are listed in Table 1. Ten of them were considered as having secondary AML on the basis of a history of previous exposure to chemotherapy or radiotherapy or a previous history of myelodysplasia, myeloproliferative disorders, or Blackfan-Diamond anemia.

Abnormal karyotypes were classified in the favorable-risk group if $\mathrm{t}(8$; $21), t(15 ; 17)$, or inv(16) was detected. In patients lacking these favorable changes, the presence of monosomy 7,11q23 abnormalities other than $\mathrm{t}(9 ; 11)$, monosomy 5 , del $(5 \mathrm{q})$, abnormal 3q, $\mathrm{t}(6 ; 9)$, or a complex karyotype defined the poor-risk group. The remaining abnormalities were classified in the intermediate-risk group.

At time of UCBT, 20 children were in first complete remission (CR1), 47 were in CR2, 5 were in third or subsequent $\mathrm{CR}$, and 23 were in relapse. Children in CR1 received transplants at a median time of 4 months after they achieved remission (range, $<1$ month to 10 months). Nine of them were in the poor-risk cytogenetic group and 2 had secondary leukemia. In the subgroup of 47 children who received transplants in CR2, the median time from CR2 to UCBT was 2 months (range, $<1$ month to 14 months); the median duration of CR 1 was 9.5 months with only 5 relapses occurring more than 18 months after CR1.

Twenty-two of the 95 children had previously received hematopoietic stem cell transplants. Eighteen had relapsed after having received a prior autologous transplantation. In the 4 remaining cases, UCBT was performed after engraftment failure of a prior unrelated bone marrow transplantation.

\section{Umbilical cord blood characteristics and transplantation procedure}

HLA-A, -B antigen serologic testing and a low-resolution generic DRB1 oligotyping were available for all cord blood transplants and recipients (Table 2). In addition, high-resolution allelic DRB1 typing of cord blood and recipient was performed in 93 of 95 cases. Using HLA-A, -B serology
Table 1. Patient and disease characteristics of children with AML given an unrelated cord blood transplant

Patient characteristics

\begin{tabular}{|c|c|}
\hline \multicolumn{2}{|l|}{ Features at diagnosis } \\
\hline Age, median (range) & $4.8 \mathrm{y}(1 \mathrm{mo}$ to $15 \mathrm{y})$ \\
\hline No. with de novo/secondary AML & $85 / 10$ \\
\hline \multicolumn{2}{|l|}{ WBC count } \\
\hline No. evaluable & $91 / 95$ \\
\hline Median (range) & $21.5 \times 10^{9} / \mathrm{L}\left(0.8-509 \times 10^{9} / \mathrm{L}\right)$ \\
\hline No. with WBC greater than $50 \times 10^{9} / \mathrm{L}(\%)$ & $29(32)$ \\
\hline \multicolumn{2}{|l|}{ FAB subtype } \\
\hline No. evaluable & $89 / 95$ \\
\hline $\mathrm{M} 0 / \mathrm{M} 1 / \mathrm{M} 2 / \mathrm{M} 3$ & $9 / 9 / 18 / 5$ \\
\hline M4/M5/M6/M7 & $16 / 21 / 3 / 8$ \\
\hline CNS involvement (\%) & $4(4)$ \\
\hline \multicolumn{2}{|l|}{ Cytogenetics (\%) } \\
\hline No. evaluable & $81 / 95$ \\
\hline Abnormal & $58(72)$ \\
\hline Relatively favorable risk & $8(10)$ \\
\hline Intermediate risk & $21(26)$ \\
\hline Poor risk & $29(36)$ \\
\hline Normal & $23(28)$ \\
\hline \multicolumn{2}{|l|}{ Features at unrelated cord blood transplantation } \\
\hline Age, median (range) & 6 y $(4$ mo to $16 y)$ \\
\hline Recipient's weight, median (range) & $21 \mathrm{~kg}(4.4-78 \mathrm{~kg})$ \\
\hline \multicolumn{2}{|l|}{ CMV serology } \\
\hline No. evaluable & $94 / 95$ \\
\hline Negative (\%) & $49(52)$ \\
\hline Positive (\%) & $45(48)$ \\
\hline \multicolumn{2}{|l|}{ Status (\%) } \\
\hline \multicolumn{2}{|l|}{ Standard-risk category } \\
\hline First CR & $20(21)$ \\
\hline Second CR & $47(50)$ \\
\hline \multicolumn{2}{|l|}{ High-risk category } \\
\hline Third or subsequent CR & $5(5)$ \\
\hline Without CR & $23(24)$ \\
\hline
\end{tabular}

WBC indicates white blood cell; FAB, French-American-British classification; CNS, central nervous system; CMV, cytomegalovirus; and CR, complete remission.

and high-resolution allelic DRB1 typing, most of the children had either 1 $(47 \%)$ or $2(33 \%)$ disparities with their graft.

As shown in Table 2, conditioning and GVHD prophylaxis regimens greatly varied among centers in this retrospective and multicenter study. A hematopoietic growth factor, most frequently granulocyte colonystimulating factor (G-CSF), was started during the early posttransplantation period (from day 0 to day +7 ) in 47 children.

\section{Statistical methods}

For this analysis, we used July 1, 2002, as the reference date (ie, the day at which all centers locked data on patient outcomes). The median duration of follow-up was 31 months (range, 3 to 92 months).

The outcome end points were neutrophil recovery, platelet recovery, GVHD, relapse, transplantation-related mortality (TRM), overall survival and leukemia-free survival (LFS). Neutrophil recovery was defined by an absolute neutrophil count (ANC) of at least $0.5 \times 10^{9} / \mathrm{L}$ for 3 consecutive days, the first of these 3 days being used as the recovery day. Platelet recovery was defined by a nontransfused platelet count of at least $20 \times 10^{9} / \mathrm{L}$ for 7 consecutive days. Death, relapse, and infusion of a stem cell rescue occurring before day 60 or day 180 were considered as competing risks for neutrophil or platelet recovery, respectively. Graft failure rates for neutrophil or platelets were calculated for patients living without relapse or autologous infusion (competing events) more than 60 or 180 days, respectively. Acute and chronic GVHD were diagnosed and graded at each center according to standard criteria. ${ }^{18,19}$ Relapse was 
Table 2. Transplant characteristics of children with AML given an unrelated cord blood transplant

\begin{tabular}{|c|c|}
\hline Unrelated cord blood characteristics & \\
\hline \multicolumn{2}{|l|}{ HLA compatibility with the recipient (\%) } \\
\hline \multicolumn{2}{|l|}{ High-resolution typing ${ }^{+}$} \\
\hline No. evaluable & $93 / 95$ \\
\hline Identical & $8(9)$ \\
\hline $1 \mathrm{HLA}$ disparity & $44(47)$ \\
\hline 2 HLA disparities & $31(33)$ \\
\hline 3 or more HLA disparities & $10(11)$ \\
\hline \multicolumn{2}{|l|}{ Low-resolution typing ${ }^{+}$} \\
\hline No. evaluable & $95 / 95$ \\
\hline Identical & $13(14)$ \\
\hline $1 \mathrm{HLA}$ disparity & $52(55)$ \\
\hline 2 HLA disparities & $28(29)$ \\
\hline 3 HLA disparities & $2(2)$ \\
\hline \multicolumn{2}{|l|}{$A B O$ compatibility with the recipient } \\
\hline No. evaluable & $94 / 95$ \\
\hline Matched & 45 \\
\hline Minor incompatibility & 24 \\
\hline Major incompatibility & 25 \\
\hline \multicolumn{2}{|l|}{ Nucleated cells collected/kg recipient } \\
\hline No. evaluable & $92 / 95$ \\
\hline Median (range) & $5.2 \times 10^{7}\left(1.2 \times 10^{7}-46.6 \times 10^{7}\right)$ \\
\hline \multicolumn{2}{|l|}{ Nucleated cells infused/kg recipient } \\
\hline No. evaluable & $94 / 95$ \\
\hline Median (range) & $4.4 \times 10^{7}\left(0.4 \times 10^{7}-36 \times 10^{7}\right)$ \\
\hline \multicolumn{2}{|l|}{ CD34 infused cells/kg recipient } \\
\hline No. evaluable & $60 / 95$ \\
\hline Median (range) & $1.38 \times 10^{5}\left(0.4 \times 10^{5}-78 \times 10^{5}\right)$ \\
\hline \multicolumn{2}{|l|}{ Transplantation characteristics } \\
\hline \multicolumn{2}{|l|}{ Conditioning regimen (\%) } \\
\hline TBI-containing & $44(46.5)$ \\
\hline Bu-containing & $47(49.5)$ \\
\hline Miscellaneous & $4(4)$ \\
\hline $\begin{array}{l}\text { Pretransplantation ATG/ALG or anti-T } \\
\text { MoAb (\%) }\end{array}$ & $72(76)$ \\
\hline $\begin{array}{l}\text { Posttransplantation growth factor, } \\
\text { started } D_{0}-D_{+7}(\%)\end{array}$ & $47(50)$ \\
\hline \multicolumn{2}{|l|}{ GVHD prophylaxis (\%) } \\
\hline Including cyclosporine A & $85(89.5)$ \\
\hline + steroids & $63(66)$ \\
\hline+ MTX & $20(21)$ \\
\hline Tacrolimus + MTX & $7(7.5)$ \\
\hline Miscellaneous & $3(3)$ \\
\hline
\end{tabular}

TBI indicates total body irradiation; Bu, Busulfan; ATG, antithymocyte globulin ALG, antilymphocyte globulin; MoAb, monoclonal antibody; $D_{0}-D_{+7}$, day 0 to day 7 after graft infusion; and MTX, methotrexate.

defined on the basis of morphologic evidence of leukemia in bone marrow or other extra-medullary organs. TRM was defined as all causes of nonleukemic deaths occurring after transplantation. Overall survival was the time between transplantation and death due to any cause. LFS was defined as time interval from UCBT to first event, either relapse or death in complete remission.

These outcomes were all right-censored. For overall survival and LFS, Kaplan-Meier estimates provided estimated incidence over time, whereas Cox models were used to evaluate the joint influence of patient-, disease-, and transplant-related variables on the outcome. However, the other end points shared a competing risks setting, that is patients could develop events that avoid the occurrence of the event of interest; as an example, after death or relapse before engraftment, no recovery and no GVHD could occur. Therefore, these end points (neutrophil and platelet recovery, acute and chronic GVHD, relapse, TRM) were analyzed through the use of cumulative incidence curves for estimating incidence over time ${ }^{20}$ and Fine and Gray models ${ }^{21}$ to assess prognostic factors.
Whatever the model, we first fit univariable models that contain each of the variables (Table 3 ) one at a time. Secondly, all variables with a $P$ value below .05 by the likelihood ratio test were included in a multivariable model. Cause-specific hazard ratios (HRs) were estimated with 95\% confidence intervals. Statistical analysis used the SAS 8.2 (Sas, Cary, NC) and S-Plus 2000 (MathSoft, Seattle, WA) software packages.

\section{Results}

\section{Neutrophil and platelet recoveries}

The cumulative incidence (CI) of neutrophil recovery at day 60 was $78 \% \pm 4 \%$ (Figure 1A). During the first 60 days after transplantation, competing risks for neutrophil recovery were death $(n=7)$, relapse $(n=5)$, and infusion of a stem cell rescue $(n=3)$. Graft failure rate for neutrophil recovery was $7.5 \%$ (6 of 80 patients). For those patients who recovered, the median time to achieve an ANC equal to or more than $0.5 \times 10^{9} / \mathrm{L}$ was 26 days (range, $12-57$ days). In the univariable analysis, factors associated with neutrophil recovery were (1) status of disease at transplantation (cumulative incidence of neutrophil recovery at day 60 was $87 \% \pm 4 \%$ for children who received transplants in CR1 or CR2 versus $57 \% \pm 10 \%$ for those with more advanced disease; $P=.01)$; (2) period of transplantation $(63 \% \pm 10 \%$ for patients treated before January 1998 versus $84 \% \pm 5 \%$ after this date; $P=.03$ ); (3) prophylactic use of hematopoietic growth factors (the cumulative incidence was $83 \% \pm 6 \%$ when a hematopoietic growth factor was started during the immediate posttransplantation period versus $73 \% \pm 7 \%$ in the other cases; $P=.015$, Figure $1 \mathrm{~B})$; and (4) methotrexate (MTX) in the GVHD prophylaxis $(63 \% \pm 10 \%$ versus $84 \% \pm 5 \%$ when MTX was not used; $P=.04)$. The association of neutrophil recovery with the nucleated cells dose was not statistically significant. In a multivariable analysis, the factors associated with an improved neutrophil recovery were standard risk status of disease at transplantation (CR1 or CR2) and prophylactic use of hematopoietic growth factor (Table 4).

The day-180 CI of platelet recovery was $58 \% \pm 5 \%$ (Figure 2A). During the first 180 days after transplantation, competing risks for platelet recovery were death $(n=18)$, relapse $(n=10)$, and infusion of a stem cell rescue $(n=4)$. Graft failure rate was $8.4 \%$ for platelet recovery ( 5 of 59 patients). For those patients who recovered, the median time to achieve platelet recovery was 52 days (range, 18-171 days). In the univariable and multivariable analyses (Table 4), the only factor, which was statistically associated with platelet recovery, was the disease status at time of transplantation. The incidence of platelet recovery by day 180 was $66 \% \pm 6 \%$ for children who received transplants in CR1 or CR2 compared with $39 \% \pm 10 \%$ in patients who received transplants in a more advanced phase $(P=.001)$. Use of prophylactic hematopoietic growth was not statistically associated with speed of platelet recovery (Figure $2 \mathrm{~B}$ ).

\section{Acute and chronic GVHD}

Acute GVHD (grade II or more) was observed in 34 patients (15 had grade II, 14 grade III, and 5 grade IV). One hundred-day cumulative incidence of acute GVHD was $35 \% \pm 5 \%$. We did not find any patient-, disease-, or transplant-related factor that could be 
Table 3. Univariable analyses of LFS after UCBT for childhood AML

\begin{tabular}{|c|c|c|}
\hline & Two-year Kaplan-Meier estimate of LFS, \%* & $P$, log-rank test \\
\hline Overall & $42 \pm 5$ & \\
\hline Diagnosis, de novo vs secondary AML & $40 \pm 6$ vs $56 \pm 16$ & .54 \\
\hline WBC count at diagnosis, less than or equal to $50 \times 10^{9} / \mathrm{L}$ vs greater than $50 \times 10^{9} / \mathrm{L}$ & $43 \pm 7$ vs $41 \pm 10$ & .67 \\
\hline Cytogenetics, "poor-risk" karyotype vs others & $44 \pm 11$ vs $40 \pm 8$ & .62 \\
\hline Age at UCBT, younger than 6 y vs $6 y$ or older & $44 \pm 7$ vs $39 \pm 6$ & .67 \\
\hline Recipient's sex, male vs female & $48 \pm 7$ vs $36 \pm 7$ & .35 \\
\hline Recipient's weight at UCBT, less than $21 \mathrm{~kg}$ vs $21 \mathrm{~kg}$ or more & $42 \pm 6$ vs $42 \pm 7$ & .96 \\
\hline Recipient's CMV serology prior to UCBT, negative vs positive & $37 \pm 7$ vs $48 \pm 7$ & .09 \\
\hline Status at UCBT & & $.002 \dagger$ \\
\hline CR1 & $59 \pm 11$ & \\
\hline CR2 & $50 \pm 8$ & \\
\hline Subsequent CR & 0 & \\
\hline No $\mathrm{CR}$ & $21 \pm 9$ & \\
\hline Previous transplantation, no vs yes & $38 \pm 6$ vs $54 \pm 11$ & .10 \\
\hline Graft/recipient HLA compatibility (high-resolution typing) & & .22 \\
\hline HLA identical & $19 \pm 15$ & \\
\hline 1 HLA disparity & $45 \pm 8$ & \\
\hline 2 HLA disparities & $37 \pm 9$ & \\
\hline 3 or more HLA disparities & $56 \pm 17$ & \\
\hline ABO compatibility, matched vs minor vs major mismatched & $51 \pm 8$ vs $42 \pm 12$ vs $28 \pm 9$ & .05 \\
\hline Collected nucleated cell dose, less than $5.2 \times 10^{7} / \mathrm{kg}$ vs $5.2 \times 10^{7} / \mathrm{kg}$ or more & $38 \pm 7$ vs $46 \pm 8$ & .46 \\
\hline Infused nucleated cell dose, less than $4.4 \times 10^{7} / \mathrm{kg}$ vs $4.4 \times 10^{7} / \mathrm{kg}$ or more & $36 \pm 7$ vs $50 \pm 8$ & .25 \\
\hline Infused CD $34^{+}$cell dose, less than $1.38 \times 10^{5} / \mathrm{kg}$ vs $1.38 \times 10^{5} / \mathrm{kg}$ or more & $34 \pm 9$ vs $52 \pm 10$ & .35 \\
\hline UCBT date, before January 1998 vs after January 1998 & $30 \pm 9$ vs $46 \pm 6$ & .04 \\
\hline Conditioning regimen, Bu-containing vs TBI-containing & $33 \pm 7$ vs $53 \pm 8$ & .10 \\
\hline Posttransplantation growth factor, no vs yes & $35 \pm 8$ vs $48 \pm 7$ & .23 \\
\hline Use of MTX for GVHD prophylaxis, no vs yes & $41 \pm 7$ vs $41 \pm 10$ & .67 \\
\hline
\end{tabular}

WBC indicates white blood cell; CMV, cytomegalovirus; TBI, total body irradiation; Bu, Busulfan; and MTX, methotrexate.

*Values given as percentage \pm SD.

associated with the incidence of acute GVHD. Notably, the number of HLA disparities between cord blood and recipient was not statistically associated with grades II to IV acute GVHD.

Two years after UCBT, the cumulative incidence of chronic GVHD was $15 \% \pm 5 \%$. Nine of 53 patients at risk presented signs of chronic GVHD (6 limited and 3 extensive).

\section{Early transplant-related mortality}

Nineteen patients died of nonleukemic causes during the first 100 days after UCBT (3 of acute GVHD, 13 of infections, and 3 of other causes). Cumulative incidence of transplantation-related mortality at day 100 was $20 \% \pm 4 \%$. In univariable analyses, the following factors were associated with increased risk of death: patients older than 6 years of age $(31 \% \pm 7 \%$ versus $10 \% \pm 4 \%$; $P=.025)$; patient's weight more than $21 \mathrm{~kg}(30 \% \pm 7 \%$ versus $11 \% \pm 5 \% ; P=.048)$; collected nucleated cell dose lower than $5.2 \times 10^{7} / \mathrm{kg}(33 \% \pm 7 \%$ versus $9 \% \pm 4 \%$ for patients receiving more than $\left.5.2 \times 10^{7} / \mathrm{kg}, P=.013\right)$; and infused nucleated cell
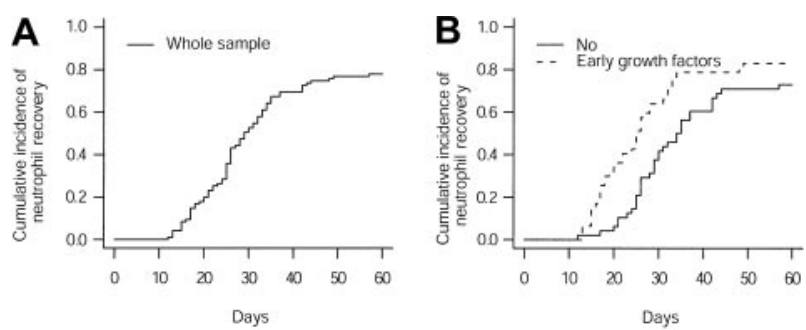

Figure 1. The cumulative incidence of neutrophil recovery. Cumulative incidence of neutrophil recovery $(A)$ and neutrophil recovery according to use of prophylactic hematopoietic growth factors $(B)$. dose lower than $4.4 \times 10^{7} / \mathrm{kg} \quad(30 \% \pm 7 \%$ versus $11 \% \pm 5 \%$ for those receiving more than $\left.4.4 \times 10^{7} / \mathrm{kg}, P=.046\right)$. There was a trend toward an increased risk of 100-day TRM when major ABO incompatibility was present $(32 \% \pm 9 \%$ versus $16 \% \pm 5 \%$ in the other cases, $P=.078)$. In multivariable analysis, the only factor associated with an increased early TRM was a low collected nucleated cell dose (less than $5.2 \times 10^{7} / \mathrm{kg}$; Figure 3 ).

\section{Relapse incidence}

Twenty-five patients had hematologic relapse after UCBT and 26 patients died without experiencing disease recurrence. Twoyear cumulative relapse incidence (RI) was $29 \% \pm 5 \%$. It was $29 \% \pm 5 \%$ in 85 patients with de novo AML and $33 \% \pm 17 \%$ in 10 patients with secondary leukemia. In univariable and multivariable analyses (Table 4), the 2 following features were associated with increased RI: patient's weight lower than $21 \mathrm{~kg}$ $(16 \% \pm 6 \%$ versus $42 \% \pm 8 \% ; P=.0001)$ and status of disease at transplantation $(19 \% \pm 5 \%$ for CR1 and 2 versus $53 \% \pm 10 \%$ for more advanced disease status; $P=.00043$ ). More precisely, the 2-year cumulative RI was $10 \% \pm 7 \%$ for patients who received transplants in CR1, 23\% $\pm 7 \%$ for patients in CR2, 1 of 5 for patients in CR3 or higher, and $61 \% \pm 11 \%$ for patients who were not in remission at time of UCBT (Figure 4A). The RI after UCBT in children presenting with poor-risk cytogenetic abnormalities was $26.5 \% \pm 10 \%$ compared with $31 \% \pm 6 \%$ in other patients. The absence of previous acute GVHD (grades II to IV) was not associated with an increased RI $(P=.62)$. In the subgroup of patients who received transplants in CR2, there was a trend toward an increased post-UCBT relapse risk for children who had suffered from an early pre-UCBT relapse (length of 
Table 4. Multivariable analyses of risk factors for the main outcomes after UCBT for childhood AML

\begin{tabular}{|c|c|c|}
\hline Factors & Hazard ratio ( $95 \%$ confidence interval) & $P$ \\
\hline \multicolumn{3}{|l|}{ Neutrophil recovery } \\
\hline CR1-2 at transplantation & $2.17(1.22-3.87)$ & .009 \\
\hline Prophylactic hematopoietic growth factor & $1.81(1.15-2.86)$ & .03 \\
\hline \multicolumn{3}{|l|}{ Platelet recovery } \\
\hline CR1-2 at transplantation & $2.21(1.17-4.17)$ & .01 \\
\hline \multicolumn{3}{|l|}{ Relapse } \\
\hline Advanced status at transplantation (CR3 or higher, no CR) & $3.84(1.66-8.33)$ & .001 \\
\hline Weight less than $21 \mathrm{~kg}$ & $2.77(1.118-6.66)$ & .02 \\
\hline \multicolumn{3}{|l|}{ Transplantation-related mortality at day 100} \\
\hline Collected nucleated cell dose less than $5.2 \times 10^{7} / \mathrm{kg}$ & $4.16(1.35-12.50)$ & .01 \\
\hline \multicolumn{3}{|l|}{ Survival } \\
\hline CR1-2 at transplantation & $2.73(1.53-5)$ & .00066 \\
\hline Major ABO incompatibility & $2.07(1.15-3.84)$ & .015 \\
\hline \multicolumn{3}{|l|}{ Leukemia-free survival } \\
\hline CR1-2 at transplantation & $2.83(1.64-5)$ & .00029 \\
\hline Major $\mathrm{ABO}$ incompatibility & $2.00(1.14-3.70)$ & .019 \\
\hline
\end{tabular}

CR indicates complete remission.

CR1 $<9.5$ months) when compared with children with later pre-UCBT relapses $(33 \% \pm 11 \%$ versus $12 \% \pm 9 \% ; P=.09)$.

\section{Leukemia-free survival, overall survival, and causes of death}

Forty-nine patients died: 23 from disease relapse, 3 of GVHD, 18 of infectious complication (bacterial 6, viral 5, fungal 5 and parasitic 2), 3 of interstitial pneumonitis, and 2 of organ failure.

Estimated 2-year overall survival and leukemia-free survival were $49 \% \pm 5 \%$ and $42 \% \pm 5 \%$, respectively. The univariable analyses of factors considered as potential predictors for 2-year LFS are detailed in Table 3. As shown in this table, the most significant factor was status of disease at time of UCBT. Two-year LFS was $59 \% \pm 11 \%$ for children who received transplants in first $\mathrm{CR}, 50 \% \pm 8 \%$ for those in second CR, none among 5 in CR3 or beyond, and $21 \% \pm 9 \%$ for children who were not in remission at time of UCBT (Figure 4B). Two other factors had a statistically significant influence: the date of transplantation and ABO compatibility between donor and recipient, with favorable outcome occurring in children who received transplants after January 1998 and without major ABO incompatibility. LFS of children with a poor prognostic karyotype was similar to LFS of other patients. In the subgroup of 47 children who received transplants while in CR2, LFS was not influenced by the length of CR1: it was $53 \% \pm 11 \%$ for patients relapsing in the first 9.5 months and $50 \% \pm 12 \%$ for those relapsing later. In multivariate analysis, 2 factors were associated with overall survival and LFS: status of the disease at transplantation and major $\mathrm{ABO}$ incompatibility (Table 4).
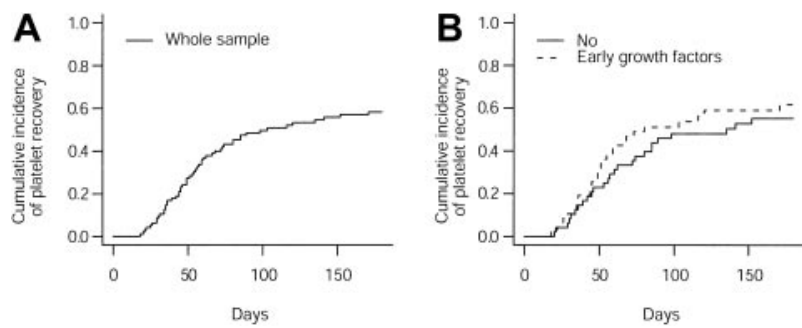

Figure 2. The cumulative incidence of platelet recovery. Cumulative incidence of platelet recovery $(A)$ and platelet recovery according to use of prophylactic hematopoietic growth factors $(\mathrm{B})$.

\section{Discussion}

This retrospective registry-based analysis is the first, to our knowledge, that was specifically designed to describe the results of UCBT in childhood AML. As expected, we found that the outcome was associated with disease status at time of transplantation. Precisely, LFS was $59 \% \pm 11 \%$ for children who received transplants in CR1, $50 \% \pm 8 \%$ in CR2, 0 of 5 in CR3 or beyond, and $21 \% \pm 9 \%$ for children who were not in remission at time of UCBT. The corresponding 2-year relapse incidences were $10 \% \pm 7 \%, 23 \% \pm 7 \%, 1$ of 5 patients, and $61 \% \pm 11 \%$. These estimated relapse incidences are comparable to those reported after BMT from an unrelated HLA-matched donor. ${ }^{2-4}$ In the Seattle experience of 161 patients with AML who received unmanipulated BM transplants from unrelated donors, the cumulative incidences of relapse were $19 \%$ in CR1, 23\% in CR2, 25\% in subsequent CR, $44 \%$ during relapse, and $63 \%$ during primary induction failure. ${ }^{2}$ In another series reported by Marks et al, ${ }^{4} 39$ patients with AML received T-cell-depleted unrelated $\mathrm{BM}$ transplants during first or second CR. Five of these 39 patients (13\%) relapsed.

We also analyzed the association of 3 well-identified prognostic factors of childhood AML such as the karyotype of malignant cells, de novo or secondary, and the duration of first CR for children who

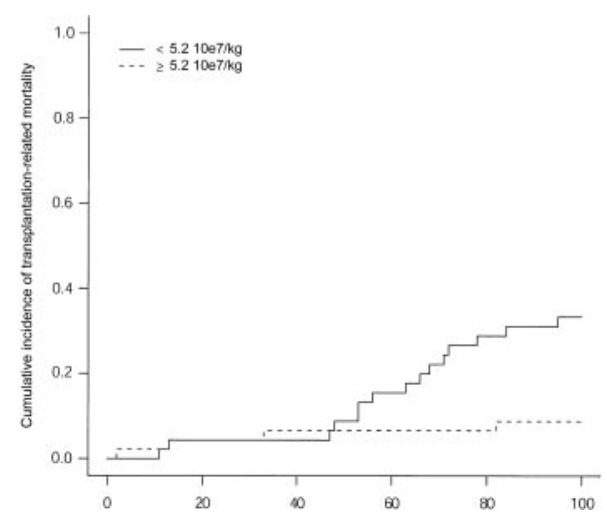

Figure 3. Collected nucleated cell dose. Cumulative incidence of 100-day transplantation-related mortality according to the median number of cells before freezing per recipient's weight. 
Figure 4. Two-year cumulative RI. Cumulative incidence of relapse $(A)$ and probability of leukemia-free survival (B) according to disease status at unrelated cord blood transplantations.

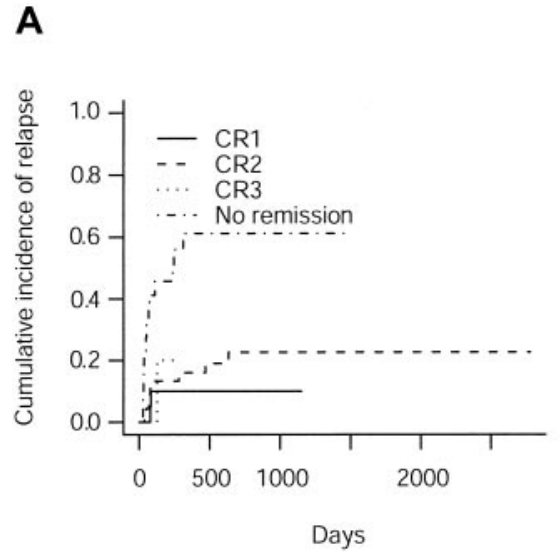

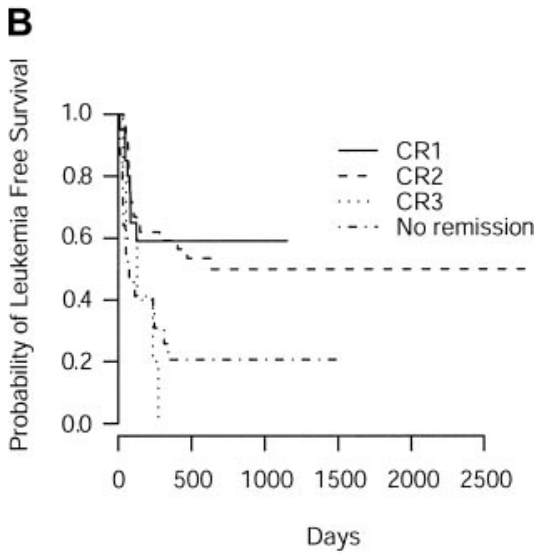

received transplants during their second CR. The karyotype of malignant cells has been shown to be one of the most relevant predictors of treatment outcome in childhood AML. ${ }^{22-27}$ In our study, $36 \%$ of the patients with a successful cytogenetic analysis were classified in the poor-risk cytogenetic category. This unusually elevated incidence for a pediatric AML population probably indicates that the patients were selected for their high risk of treatment failure. Interestingly, children with a poor karyotype had similar 2-year LFS and a similar incidence of relapse compared with other patients $(44 \% \pm 11 \%$ versus $40 \% \pm 8 \%$ and $26.5 \% \pm 10 \%$ versus $31 \% \pm 6 \%$, respectively). Children with secondary leukemia are usually considered as having more aggressive disease than children with de novo AML. Only 10 children in this study had secondary leukemia but their outcome after UCBT did not differ from that of children with de novo AML. The length of first remission has been demonstrated to be a major prognostic factor for children with relapsed AML. ${ }^{28-29}$ We tested the potential influence of the length of first remission in the subgroup of children that received transplants in CR2 and did not find any correlation between this variable and LFS, although there was a trend toward a lower rate of relapse in patients with more prolonged CR1. Taken together, our results suggest that these 3 prognostic factors, identified in patients with AML undergoing contemporary chemotherapy or standard allogeneic BMT, may not have the same predictive value in the context of unrelated UCBT. This apparently potent antileukemic effect in poor-risk AML does not support the hypothesis of an inadequate GVL effect after UCBT.

In our study, the 100-day cumulative incidence of TRM was $20 \% \pm 4 \%$. This high incidence is similar to the ones reported in other series of children receiving UCB transplants. ${ }^{17,30-32}$ Clearly, TRM is currently the principal obstacle for a wider use of UCBT in children with high-risk AML as well as in many other diseases. In our analysis, TRM was $17 \% \pm 5 \%$ in transplantations carried out after January 1998 and 30\% $\pm 9 \%$ before this date. Moreover, when the collected nucleated cell dose was above the median $\left(5.2 \times 10^{7} / \mathrm{kg}\right)$, the 100 -day TRM decreased to $9 \% \pm 4 \%$. The same effect on TRM was found when the analyzed variable was the infused cell dose with a TRM of $11 \% \pm 5 \%$ for children receiving a cell dose above the median value. The influence of the graft nucleated cell dose on posttransplantation outcome has been consistently demonstrated since the first reports of successful UCBT. Gluckman et al $^{14}$ first demonstrated that children who received more than $3.7 \times 10^{7}$ nucleated cells $/ \mathrm{kg}$, the median infused cell dose in their series, had better outcome than children who received a lower cell dose. More recently, Wagner et $\mathrm{al}^{33}$ showed that the infused $\mathrm{CD}_{3} 4^{+}$cell dose was a more potent indicator of prognosis than the nucleated cell dose. They described a threshold of $1.7 \times 10^{5} \mathrm{CD} 34^{+}$cells $/ \mathrm{kg}$ and suggested that UCB units containing less than this $\mathrm{CD} 34^{+}$cell dose should be considered inadequate to routine use because of a very high TRM risk. ${ }^{33}$ In fact, whatever the cell dose criteria may be, it probably has to be interpreted in the context of HLA disparity. Several studies have recently suggested that the impact of cell dose could be more significant when the graft/recipient HLA-incompatibility increases..$^{15,33,34}$ These issues are crucial in the choice of an umbilical cord transplantation for a given patient but will be more efficiently addressed in large registry studies than in a disease-specific study like ours.

Of note, the primary cause of nonleukemic death in our series of 95 children was more frequently infection ( $\mathrm{n}=18$ cases) than GVHD $(n=3)$. The fact that most deaths were secondary to infections has important implications for the clinical care of children treated with UCBT. In addition to the choice of a CB graft with high cell counts, improved prophylaxis, prompter diagnosis, and treatment of infectious complications may have a major impact on the outcome of these patients. The relatively low incidence of lethal GVHD and the high risk of infectious complications raise questions on the intensity of posttransplantation immunosuppressive therapy. In order to clarify these important issues, carefully designed prospective trials are needed.

We conclude that UCBT is a good treatment for children with AML who have a very high risk of treatment failure under chemotherapy and who lack an HLA-compatible sibling. The results of UCBT were particularly promising for children with secondary leukemia, a poor prognosis karyotype, and in children who received transplants in CR2 after an early relapse.

\section{Acknowledgments}

We would like to thank S. Armitage and M. Contreras (London CBB); S. Querol and J. Garcia (Barcelona CB); L. Lecchi and P. Rebulla (Milan-Grace CBB); P. Rubinstein (NY CBB); T. Nagamura (Tokyo CBB); C. Oswald and M. Vowels (Sydney CBB); G. Koegler, P. Horn, and P. Wernet (Düsseldorf CBB); V. Bons (Eurocord, Paris); and all data managers from Eurocord centers who collaborated with this study. 


\section{Appendix}

\section{Participating centers and number of transplantations reported (childhood AML)}

\begin{tabular}{|c|c|c|c|}
\hline Centers & Location & Principal Investigator(s) & No. of cases \\
\hline Univ. La Sapienza, and Ospedale Pediatrico Bambini Gesu & Rome, Italy & Drs W. Arcese, M. Caniglia & 8 \\
\hline Children's Hospital Medical Centre & Cincinnati, $\mathrm{OH}$ & Dr A. Filipovich & 5 \\
\hline MD Anderson Cancer Centre & Houston, TX & Dr K.-W. Chan & 5 \\
\hline Hôpital Pédiatrique La Timone & Marseille, France & Pr G. Michel & 4 \\
\hline Sydney Children' Hospital & Randwick, Australia & Prs M. Vowels, C. Oswald & 4 \\
\hline Hôpital d'Enfants & Vandoeuvre Nancy, France & Pr P. Bordigoni & 3 \\
\hline Hospital M infantil Vall d'Hebron & Barcelona, Spain & Pr J. Orlega & 3 \\
\hline The New Children's Hospital & Sydney, Australia & DrP. Shaw & 3 \\
\hline BMT Unit Schneider Children's & Petach-Tikva, Israel & Drs I. Yaniv, J. Stein & 3 \\
\hline Inst Portugues Oncologia & Lisboa, Portugal & Drs M. Abecassis, A. Machado & 2 \\
\hline Hospital Infantil La Fe & Valencia, Spain & Drs A. Verdeguer, V. Castel & 2 \\
\hline FLENI & Buenos Aires, Argentina & Dr B. Diez & 2 \\
\hline Ospedale Regine Margherita & Torino, Italy & Dr F. Fagioli & 2 \\
\hline Hospital Israelita A. Einstein & Sao Paulo, Brasil & Dr E. Ferreira & 2 \\
\hline Hôpital Saint Louis & Paris, France & Pr E. Gluckman & 2 \\
\hline Hôpital Claude Huriez & Lille, France & Pr J. P. Jouet & 2 \\
\hline IRCC Policlinico San Matteo & Pavia, Italy & Dr F. Locatelli & 2 \\
\hline Hospital de Clinicas & Curitiba, Brasil & Dr R. Pasquini & 2 \\
\hline Inst. Portugues Oncologia & Porto, Portugal & Dr P. Pimentel & 2 \\
\hline City of Hope Medical School & Duarte, $C A$ & Dr J. Rosenthal & 2 \\
\hline FHCRC & Seattle, WA & Drs E. Sievers, A. Mellon & 2 \\
\hline Clinica Oncoematologia Pediatrica & Padova, Italy & Drs L. Zanesco, C. Messina & 2 \\
\hline Univ. Hospital Lund & Lund, Sweden & Dr A. Bekassy & 1 \\
\hline Inst. Paoli Calmette & Marseille, France & Pr D. Blaise & 1 \\
\hline Lombardi Cancer Center & Washington, DC & Dr M. Cairo & 1 \\
\hline Hôpital Saint Justine & Montreal, QC, Canada & Dr M. Champagne & 1 \\
\hline Hôpital/Cantonal Universitaire & Geneva, Switzerland & Dr B. Chapuis & 1 \\
\hline Inst. G. Gaslini & Genova, Italy & Dr S. Dallorso & 1 \\
\hline Children's Hospital Oakland & Oakland, CA & Dr M. Walters & 1 \\
\hline Inst. di clinica pediatrica & Pisa, Italy & Dr C. Favre & 1 \\
\hline St Sophia Children's Hospital & Athens, Greece & Drs S. Grafakos, J. Peristeri & 1 \\
\hline Hôpital de l'Archet & Nice, France & Dr N. Gratecos & 1 \\
\hline Medical City Dallas Hospital & Dallas, TX & RN M. Hooker & 1 \\
\hline Tokai Univ. School of Medicine & Isehara, Japan & Dr S. Kato & 1 \\
\hline Prince of Wales Hospital & Hong Kong, China & Dr C. K. Li & 1 \\
\hline Hospital Nino Jesus of Madrid & Madrid, Spain & Dr L. M. Madero & 1 \\
\hline Hospital Infantil La Paz & Madrid, Spain & Dr A. M. Martinez-Rubio & 1 \\
\hline ITMO & La Plata, Argentina & Dr J. Milone & 1 \\
\hline Hadassah Univ. Hospital & Jerusalem, Israel & Drs A. Nagler, S. Slavin & 1 \\
\hline Univ. of Bologna & Bologna, Italy & Dr A. Pession & 1 \\
\hline Hôpital La Miletrie & Poitiers, France & Dr A. Sadoun & 1 \\
\hline CETRAMOR & Rosario, Argentina & Drs J. Saslavski, J. Cozzi & 1 \\
\hline Ospedale V Cervello & Palermo, Italy & Dr R. Scime & 1 \\
\hline James Whitcomb Riley Hospital for Children & Indianapolis, IN & Dr F. Smith & 1 \\
\hline Royal Children's Hospital & Melbourne, Australia & Dr K. Tiedemann & 1 \\
\hline Heinrich-Heine-Univ. & Düsseldorf, Germany & Dr U. Göbel & 1 \\
\hline Sheffield Children's Hospital & Sheffield, United Kingdom & Dr A. Vora & 1 \\
\hline Martin Luther Univ.-Wittenberg Ktinik for Kinder & Halle, Germany & Dr A. Wawer & 1 \\
\hline Sapporo Med. Univ. & Sapporo, Japan & Dr R. Kudo & 1 \\
\hline Yokohama City Univ. & Yokohama, Japan & Dr H. Fujii & 1 \\
\hline Kyoto Univ. & Kyoto, Japan & Dr Tatsutoshi Nakahata, Dr Y.-W. Lin & 1 \\
\hline Yamaguchi Univ. Hospital & Yamaguchi, Japan & Dr H. Ayukawa & 1 \\
\hline Ibaragi Prefecture Children's Hospital & Mito, Japan & Dr M. Tsuchida & 1 \\
\hline
\end{tabular}

\section{References}

1. Balduzzi A, Gooley T, Anasetti C, et al. Unrelated donor marrow transplantation in children. Blood. 1995;86:3247-3256.

2. Sierra J, Storer B, Hansen JA, et al. Unrelated donor marrow transplantation for acute myeloid leukemia: an update of the Seattle experience. Bone Marrow Transplant. 2000;26:397-404.

3. Chown SR, Marks DI, Cornish JM, et al. Unrelated donor bone marrow transplantation in children and young adults with acute myeloid leukemia in remission. Br J Haematol. 1997;99:36-40.
4. Marks DI, Bird JM, Vettenranta K, et al. T celldepleted unrelated donor bone marrow transplantation for acute myeloid leukemia. Biol Blood Marrow Transplant. 2000;6:646-653.

5. Davies SM, Wagner JR, Shu XO, et al. Unrelated donor bone marrow transplantation for children 
with acute leukemia. J Clin Oncol. 1997;15:557565.

6. Hongeng S, Krance RA, Bowman LC, et al. Outcomes of transplantation with matched-sibling and unrelated-donor bone marrow in children with leukaemia. Lancet. 1997;350:767-771.

7. Beatty PG, Anasetti C, Hansen JA, et al. Marrow transplantation from unrelated donors from the treatment of hematologic malignancies: effect of mismatching for one HLA locus. Blood. 1993;81: 249-253.

8. Davies SM, Shu XO, Blazar PR, et al. Unrelated donor bone marrow transplant: influence of HLA-A and B incompatibility on outcome. Blood. 1995;86:1636-1642.

9. Petersdorf EW, Longton GM, Anasetti $\mathrm{C}$, et al The significance of HLA-DRB1 matching on clinical outcome after HLA-A, B, DR identical unrelated donor marrow transplantation. Blood. 1995 85:1606-1613.

10. Aversa F, Terenzi A, Felicini R, et al. Mismatched T-cell depleted hematopoietic stem cell transplantation for children with high-risk acute leukemia. Bone Marrow Transplant. 1998;22:S29-S32.

11. Handgretinger R, Klingebiel T, Lang P, et al. Megadose transplantation of purified peripheral blood $\mathrm{CD}_{4}{ }^{+}$progenitor cells from HLA-matched parental donors in children. Bone Marrow Transplant. 2001;27:777-783.

12. Kurtzberg J, Laughlin M, Graham ML, et al. Placental blood as a source of hematopoietic stem cells for transplantation in unrelated recipients. N Engl J Med. 1996;335:157-166.

13. Wagner JE, Rosenthal J, Sweetman R, et al. Successful transplantation of HLA-matched and HLAmismatched umbilical cord blood from unrelated donors: analysis of engraftment and acute graftversus-host-disease. Blood. 1996;88:795-802.

14. Gluckman E, Rocha V, Boyer-Chammard A, et al. Outcome of cord-blood transplantation from related and unrelated donors. N Engl J Med. 1997; 337:373-381.

15. Rubinstein P, Carrier C, Scaradavou A, et al. Outcome among 562 recipients of placental blood transplants from unrelated donors. N Engl J Med. 1998;339:1564-1577.
16. Barker JN, Krepski TP, DeFor T, Davies SM, Wagner JE, Weisdorf DJ. Searching for unrelated donor hematopoietic stem cell grafts: availability and speed of umbilical cord blood versus bone marrow. Biol Blood Marrow Transplant. 2002;8: 257-260.

17. Rocha V, Cornish J, Sievers EL, et al. Comparison of outcome of unrelated bone marrow and umbilical cord blood transplants in children with acute leukemia. Blood. 2001;97:2962-2971.

18. Glucksberg H, Storb R, Fefer A, et al. Clinical manifestations of graft-versus-host disease in human recipients of marrow from HLA-matched sibling donors. Transplantation. 1974;18: 295-304.

19. Storb R, Prentice RL, Sullivan KM, et al. Predictive factors in chronic graft-versus-host disease in patients with aplastic anemia treated by bone marrow transplantation from HLA-identical siblings. Ann Intern Med. 1983;98:461-466.

20. Gooley TA, Leisenring W, Crowley J, Storer BE. Estimation of failure probabilities in the presence of competing risks: new representations of old estimators. Stat Med. 1999;18:695-706

21. Fine JP, Gray RJ. A proportional hazards model for the sub distribution of a competing risk. JAMA. 1999;94:496-509.

22. Martinez-Climent JA, Lane NJ, Rubin CM. Clinical and prognostic significance of chromosomal abnormalities in childhood acute myeloid leukemia de novo. Leukemia. 1995;9:95-101.

23. Grimwade D, Walker H, Oliver F, et al, for the Medical Research Council Adult and Children's Leukemia Working Parties. The importance of diagnostic cytogenetics on outcome in AML: analysis of 1,612 patients entered into the MRC AML10 trial. Blood. 1998:92:2322-2333.

24. Wheatley K, Burnett AK, Goldstone AH, et al, for the United Kingdom Medical Research Council Adult and Children's Leukemia Working Parties. A simple, robust, validated and highly predictive index for the determination of risk-directed therapy in acute myeloid leukemia derived from the MRC AML 10 trial. Br J Haematol. 1999;107: 69-79.

25. Pui $\mathrm{CH}$, Boehm FG. Pathology of acute myeloid leukemia. In: Lilleyman J, Hann I, Blanchette V, eds. Pediatric Hematology. Edinburgh, Scotland: Churchill Livingstone; 2000:369-385.

26. Luna-Fineman S, Shannon KM, Lange BJ. Childhood monosomy 7: epidemiology, biology, and mechanistic implications. Blood. 1995;85:19851999.

27. Soekarman $D$, von Lindern $M$, Daenen $S$, et al. The translocation $\mathrm{t}(6 ; 9)$ (p23; q34) shows consistent rearrangement of two genes and defines a myeloproliferative disorder with specific clinical features. Blood. 1992;79:2990-2997.

28. Webb DKH, Weatley K, Harrison G, Stevens RF Hann IM, for the MRC Childhood Leukemia Working Party. Outcome for children with relapsed acute myeloid leukemia following initial therapy in the MRC AML 10 trial. Leukemia. 1999;13:25-31.

29. Stahnke K, Boos J, Bender-Götze C, Ritter J, Zimmermann M, Creutzig U. Duration of first remission predicts remission rates and long-term survival in children with relapsed acute myelogenous leukemia. Leukemia. 1998;12:1534-1538.

30. Ohnuma K, Isoyama K, Ikuta K, et al. Cord blood transplantation from HLA-mismatched unrelated donors as a treatment for children with haematological malignancies. Br J Haematol. 2001;112: 981-987.

31. Barker JN, Davies SM, DeFor T, Ramsay NK, Weisdorf DJ, Wagner JE. Survival after transplantation of unrelated donor umbilical cord blood is comparable to that of HLA-matched unrelated donor bone marrow: results of a matched-pair analysis. Blood. 2001;97:2957-2961.

32. Locatelli F, Rocha V, Chastang C, et al, for Eurocord-Cord Blood Transplant Group. Factors associated with outcome after cord blood transplantation in children with acute leukemia. Blood. 1999; 93:3662-3671.

33. Wagner JE, Barker JN, DeFor TE, et al. Trans plantation of unrelated donor umbilical cord blood in 102 patients with malignant and non-malignant diseases: influence of CD34 cell dose and HLA disparity on treatment-related mortality and survival. Blood. 2002;100:1611-1618.

34. Gluckman E, Rocha V, Chevret S, et al. Factors associated with outcome of unrelated cord blood transplant: guidelines for donor choice: an Eurocord study [abstract]. Blood. 2002;100:2527a. 